\title{
Late Presentation of HIV (Human Immunodeficiency Virus) Infection at a District General Hospital
}

Dr Ceri Williams, Dr Kathir Yoganathan, Dr Susannah Danino, Dr Soumeya Cherif, Department of GUM and HIV, Singleton Hospital, Sketty Lane, Swansea, SA2 8QA

\section{Introduction}

A significant proportion of patients (390/6360 (6.1\%) in 2012 nationally) present with an AIDS defining illness yearly despite increasing awareness and recognition of HIV. In 2012 new guidance was released by the British HIV Association (BHIVA) for the treatment of HIV recommending that Anti-Retroviral Therapy (ART) should be started in newly diagnosed patients if either their CD4 count $<350$ cells/mm ${ }^{3}$, they had an AIDS defining illness or a neurological complication. A re-audit was performed following previous audits in the ABMU Health Board in 2006/07 and 2011/2012 to ascertain whether late presentation of HIV has improved.

\section{Method}

A retrospective study compiled data from case notes of all patients diagnosed with HIV between 01/01/2014 and 31/12/2015. Patients for the study were identified through the department database. Late presenters were defined as those with an AIDS defining illness or a CD4 count $<350$ cells $/ \mathrm{mm}^{3}$. This was the same parameter used as in the previous $2011 / 12$ audit.

\section{Results}

100 Patients were registered in the clinic between $1^{\text {st }}$ January 2014 and $31^{\text {st }}$ December 2015. Of these, there were 33 transfers who were excluded from the trial as they had been previously diagnosed with HIV.

Of the remaining 67 patients $82.1 \%$ were male and $17.9 \%$ female. There were $56.7 \%$ heterosexuals, $38.8 \%$ homosexuals and $4.5 \%$ bisexuals.

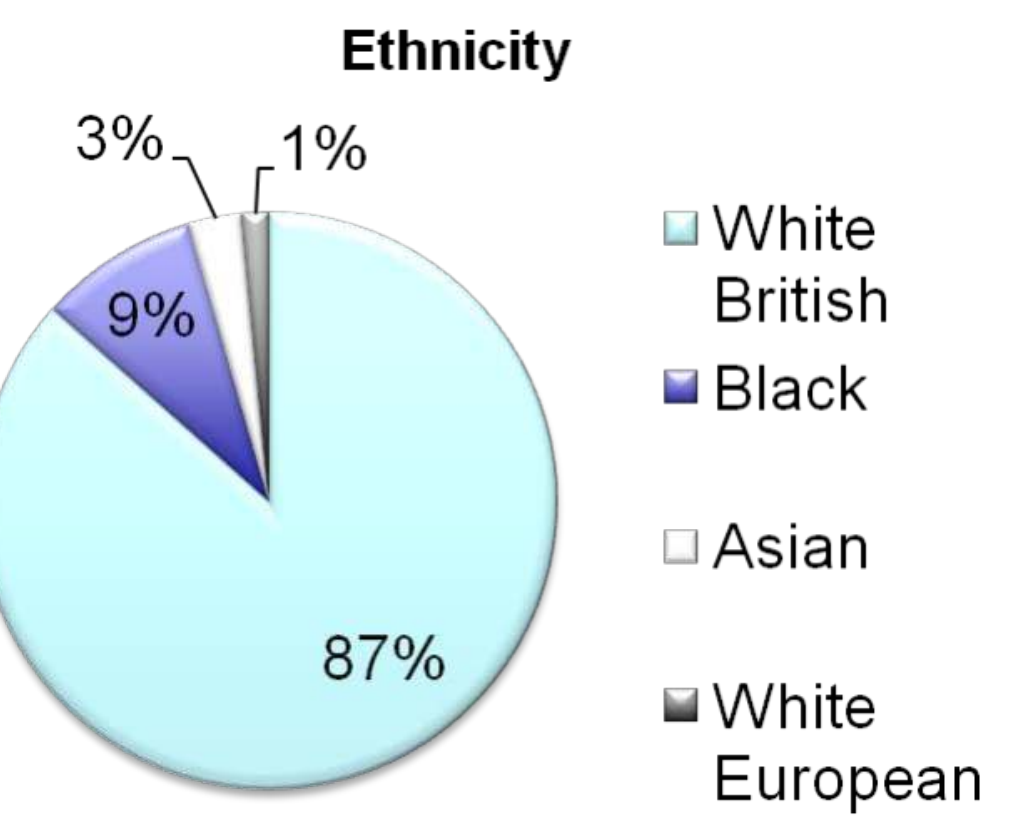

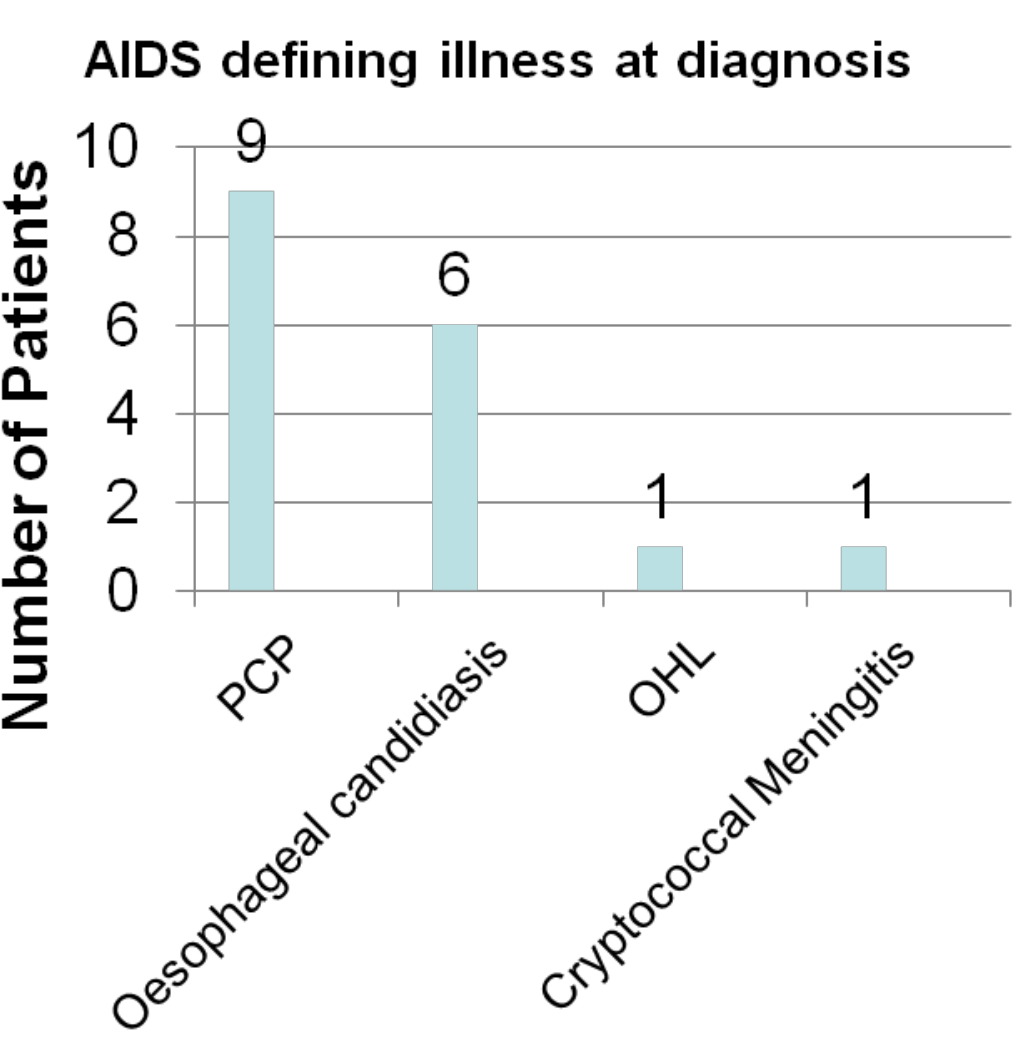

The remaining 67 patients had a new diagnosis of HIV in the ABMU trust. Of these, $35(52.2 \%)$ were classed as late presenters. (AIDS defining illness or a CD4 count $<350$ cells $/ \mathrm{mm}^{3}$ ). A total of $25.4 \%$ patients presented with an AIDS defining illness of which 9 had PCP, 6 had oesophageal candidiasis, 1 had cryptococcal meningitis and 1 had oral hairy leukoplakia.
Overall 24 out of 67 patients (35.8\%) had a CD4 $<200$ cells $/ \mathrm{mm}^{3}$, as did $68 \%$ of the late presenters and $66.7 \%$ of patients with an AIDS defining illness.

\section{Late presenters with CD4 count of $<200$ cells $/ \mathrm{mm}^{3}$}

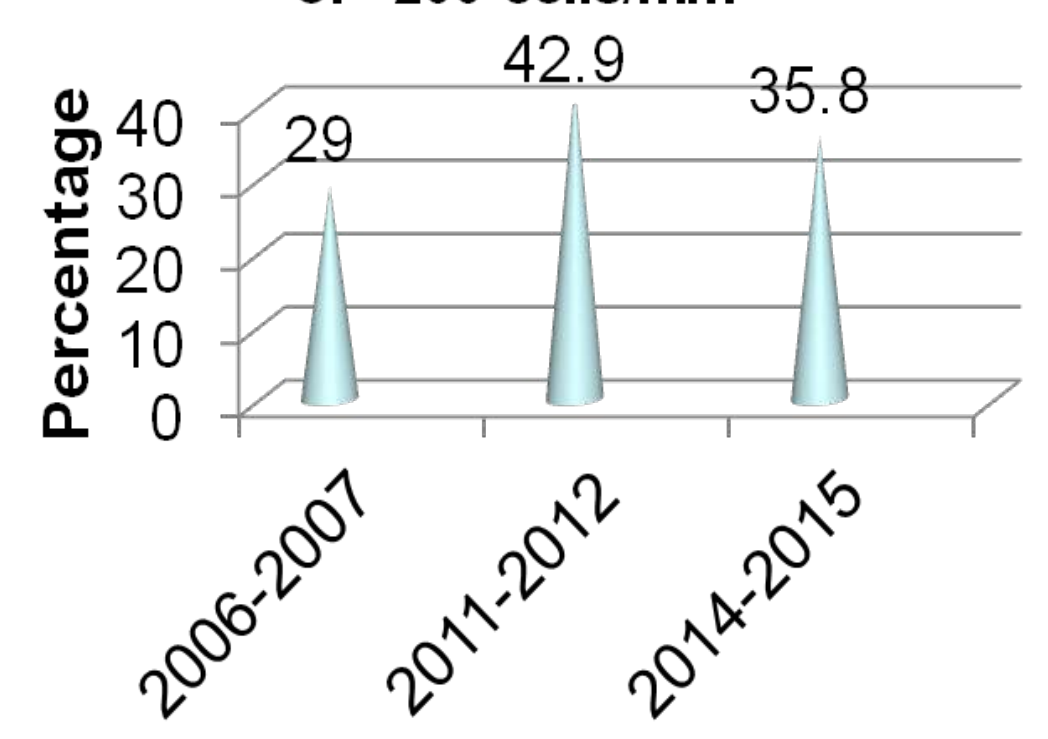

$98.5 \%$ of newly diagnosed patients had a detectable viral load at diagnosis; the remaining $1.5 \%$ ( 1 patient) did not have a viral load tested at diagnosis due to a transport delay with the sample reaching the laboratory.

\section{Discussion}

$35.8 \%$ of patients in 2014/15 had a CD4 count of $<200$ cells $/ \mathrm{mm}^{3}$ at diagnosis compared to $42.9 \%$ and $29 \%$ in 2011/12 and 2006/07 respectively. This highlights a slight improvement on the most recent audit only. The percentage detected with a CD4 $<350$ cells $/ \mathrm{mm}^{3}$ was $52.2 \%$ again an improvement on the $55.7 \%$ in the $2011-12$ audit.

A high proportion of patients still present with decreased or depleted levels of CD4 despite a growing awareness of HIV and accessibility to health care. Evidence suggests that those presenting late have a clinically worse prognosis and increased rate of mortality.

\section{Key Messages}

Clinicians need to be encouraged to be proactive and recognise clinically the risk factors and symptoms which may be suggestive of HIV. Atypical and opportunistic infections should prompt HIV testing amongst clinicians in both primary and secondary care along with improving patient education and contact tracing to minimize late presentation.

Despite many of the early symptoms being subtle and a proportion overlapping other common medical conditions all patients with an AIDS defining illness should receive prompt HIV testing.

The introduction and implementation of routine HIV testing in appropriate settings such as GUM clinics, antenatal settings and termination of pregnancy services would contribute to decreasing the diagnostic delay and number of late presenters. 